\title{
Análisis de la percepción de jóvenes universitarios respecto a la sintonía de programas televisivos con contenido religioso y de conflicto social durante la pandemia de COVID-19, Perú 2020
}

\section{Analysis of the perception of young university students regarding the tuning of television programs with religious content of social conflict during the context of the COVID-19 pandemic, Peru 2020}

Recibido: 28/10/2020

Aceptado: 20/05/2021

Publicado: 30/06/2021
Segundo Serrato Sánchez segundo.serrato@gmail.com https://orcid.org/0000-0003-0350-3669

Universidad Jaime Bausate y Meza (Perú)

Resumen: Durante la cuarentena establecida por la pandemia por COVID-19, las familias peruanas ampliaron su horario de atención a la televisión, y demostraron preferencia por programas que presentan temas vinculados a la religiosidad y a la violencia doméstica. Sobre la base de una sistematización de los ratings de audiencia en Lima y seis regiones, se investigó la percepción de jóvenes universitarios respecto a las razones de esta preferencia. Se aplicó una encuesta a 100 jóvenes universitarios sobre el rating registrado entre el 15 de marzo y el 30 de junio del año 2020 de la telenovela "La rosa de Guadalupe" (en versiones mexicana y peruana) y del dominical "Nunca más". Se concluyó que ambos programas son preferidos porque reflejan situaciones que son familiares y se asemejan a la realidad. Se evidencia, además, que la televisión es el medio más influyente para la difusión de los patrones sociales, 
por su presencia hegemónica en los hogares y por su gran fuerza expresiva para trasmitir mensajes de la vida cotidiana.

Palabras clave: Valores religiosos, Religiosidad, Preferencias televisivas, Telenovelas.

Abstract: During the quarantine established by the COVID-19 pandemic, peruvian families extended their hours of attention to television, and demonstrated a preference for programs that present topics related to religiosity and domestic violence. Based on a systematization of audience ratings in Lima and six regions, the perception of young university students regarding the reasons for this preference was investigated. A survey was applied to 100 young university students about the rating registered between March 15 and June 30, 2020, of the soap opera "La rosa de Guadalupe" (in Mexican and Peruvian versions) and the "Nunca más". It was concluded that both programs are preferred because they reflect situations that are familiar and resemble reality. It is also evidenced that television is the most influential medium for the dissemination of social patterns, due to its hegemonic presence in homes and due to its great expressive force to transmit messages from daily life.

Keywords: Religious values, Religiosity, Television preferences, Soap operas.

\section{Introducción}

El 15 de marzo de 2020, el entonces presidente peruano, Martín Vizcarra Cornejo, dispuso el inicio de una prolongada cuarentena en el Perú a consecuencia de la pandemia del nuevo coronavirus (síndrome respiratorio agudo severo o SARS-Cov-2), causante de la enfermedad pulmonar denominada COVID-19. La epidemia se inició en diciembre de 2019 en el mundo, y la medida restrictiva en este país sudamericano culminó el 30 de junio; es decir, se mantuvo durante 107 días.

En este lapso de acuartelamiento en los hogares peruanos, las familias ampliaron su horario de atención a la televisión, a la cual ya dedicaban aproximadamente 
3,18 horas al día antes del 15 de marzo. Durante la cuarentena, este tiempo pasó a 6,41 horas en promedio, según reveló el registro de Kantar Ibope Media (Diario El Comercio digital, 2020) levantado en la semana del 6 al 12 de abril. Además, registró un $42 \%$ de aumento de televidentes.

Otros gobiernos, como el de México, también adoptaron restricciones a la libre circulación a consecuencia de la COVID-19 y, como en el Perú, las horas libres en las familias fueron dirigidas hacia la pantalla chica, registrándose una cifra de hasta 6.6 de personas sintonizando el canal Televisa, en el horario estelar.

En el Perú, el televisor es el equipo de mayor presencia en los hogares entre los artefactos electrodomésticos, solo después de la cocina. Un estudio de Soluciones \& Consultoría de marketing (2019) señala que la televisión es el medio que más se utiliza, tanto "de lunes a viernes (99\%), como durante el fin de semana (97\%) y que, en las ciudades evaluadas, el porcentaje es elevado: entre $89 \%$ y $100 \%$ de lunes a viernes, y de $79 \%$ a $100 \%$ el fin de semana" (p.9). También es el medio al que se le dedica mayor cantidad de horas al día.

Según el estudio realizado por el Consejo Consultivo de Radio y Televisión (Concortv), en Lima el 98,7 \% tiene un equipo en casa, mientras que el porcentaje es de $98,3 \%$ en las capitales de las regiones. Esto revela que no solo la población de las grandes ciudades está integrada al lenguaje e imagen que trasmite la televisión, sino también la población periférica urbana, la que, para algunos analistas, es población rural, especialmente la afincada en los distritos con energía eléctrica.

El análisis sobre los clientes de la televisión abierta, que se emite en el Perú en 2020, lleva a diferenciar cinco rubros de programación (también llamada parrilla):

a) Entretenimiento (películas, concursos, musicales, series, telenovelas)

b) Noticieros

c) De contenido político

d) De contenido social

e) De contenido religioso 


\subsection{El factor religioso en la televisión}

Las creencias religiosas son parte de la vida social, cultural y política de la sociedad desde la creación de la humanidad. La televisión, como medio de comunicación referente de la realidad social, se ha adecuado a esta expresión, explorando y explotando los temas con contenido religioso. Es el caso de "La rosa de Guadalupe", donde los problemas sociales son solucionados luego de la invocación a la Virgen, la que concede un milagro que acontece como el fin del conflicto en la historia.

Turner (como se citó en Ramírez \& Torres, 2009) concluyó que "la Virgen de Guadalupe es el referente dominante de los mexicanos en el catolicismo y en el nacionalismo patriótico" (p.201), pues fue y es el símbolo más potente de mestizaje cultural. Además, precisa el autor que el ícono religioso condensa la identificación de los más pobres, de los indígenas, de las minorías estigmatizadas, de los excluidos y de los que no tienen voz. El estudio se refiere solo a la feligresía local; no obstante, siendo así, cabe preguntarse por qué se extendió su fidelidad a otras latitudes.

Según Vásquez (2011), "la religión católica es asociada a una red de educación que impone ciertas formas de comportamiento vistas como "correctas e incorrectas"' (p.1) y, por ello, la televisión es la ventana para abordar los temas de interés social, como lo son las relaciones amorosas y algunos problemas sociales por los que atraviesa la población.

Sobre el particular, Garcés (2015) sostiene que en Latinoamérica hay una mayor identificación del público católico con la Virgen de Guadalupe, conocida como "La Morenita", porque "al ser la única Virgen india, que además rompe el mito de las vírgenes rubias, blancas y de canon europeo, produce sentimientos de identificación con aquellos tradicionalmente relegados por el poder" (p.59). Por ello, en cierta forma permite la visibilización y enunciación ya no solo desde la élite mestizo-criolla, sino también desde lo subalterno, entre lo que figura principalmente lo indígena. En consecuencia, hay una asociación multicultural sin fronteras en torno a ella.

Es en ese contexto que miles de televidentes se ven representados en este ícono religioso por esta corriente del guadalupismo, considerada por sus 
estudiosos como "el consuelo de los pobres, el escudo de los débiles, el amparo de los oprimidos, o la madre de los huérfanos".

El Perú tiene a santas reconocidas como Rosa de Lima, bautizada como "Patrona de América y primera santa iberoamericana", canonizada en 1671 por el papa Clemente X. Ella tuvo, además, mucha influencia en el fortalecimiento de los dominicos en el Perú y las Indias, entre los siglos XVII y XVIII. Dada su influencia social y espiritual en un vasto sector social, la cadena EWTN hizo una miniserie de cinco capítulos como parte de la serie de patronos peruanos, la cual fue trasmitida en 95 países.

\subsection{La televisión como medio de exposición de los conflictos sociales- familiares}

La exposición de los conflictos sociales o familiares en la televisión se inició en la década de 1990, con lo cual se puso en evidencia la agresión hacia la mujer y el feminicidio. Pero, si bien fue importante la difusión de este problema social, se produjo también un abuso de la exposición de la violencia.

Atendiendo a esa preocupación, en 2011 el Ministerio de la Mujer y Poblaciones Vulnerables elaboró las pautas para el tratamiento informativo adecuado de la violencia contra la mujer. No obstante, los medios de comunicación siguen exponiendo la agresión a la mujer y situaciones de violencia incluso en horarios considerados familiares, aun con las sanciones como las que impuso Concortv el 18 de julio de 2016, precisamente al programa Nunca más, por la exposición de casos de crisis y violencia en los hogares, dentro del horario familiar.

Si bien la familia ha mostrado transformaciones en su estructura, la sociedad ha generado que esas estructuras se diversifiquen, al punto de presentar variados tipos y con problemáticas distintas, aunque manteniendo la estructura patriarcal, jerárquica y autoritaria, situación presentada en la televisión, exacerbando la violencia y el drama.

Como indicó França (2001), las producciones en las series televisivas realizan las narraciones en función de los intereses de las cadenas y, 
principalmente, de los auspiciadores. En ese sentido, la televisión se convierte en una creación ficticia, que tiene un propósito: generar mercado y ampliar la necesidad de consumo de los televidentes.

La televisión, entonces, se ha convertido en el medio de comunicación más influyente cuando se trata de mostrar estos patrones diferentes de comportamiento de las audiencias; que llevan incluso a viralizar frases como "el arroz chaufa es sagrado". Ello en alusión a la respuesta que dio una víctima de violencia familiar que, a pesar de las agresiones de su pareja, aceptaba continuar viviendo en el mismo techo con el atacante porque le facilitaba este plato referente en la gastronomía popular.

Este fenómeno ocurriría, como dice Bourdieu (2000), porque "las mujeres aplican a cualquier realidad unos esquemas mentales en las relaciones de poder donde están atrapadas" (p.49). Y dado que existe un público que solicita este tipo de eventos, se muestran tal cual, sin importar el nivel moral, intelectual y ético de una gran mayoría de la sociedad.

La programación tiene en su parrilla un componente siempre presente. Se trata de las telenovelas, donde se exhiben guías para un determinado público, como los valores de amor eterno, la religiosidad, carga emocional, además de recompensas por la virtud y castigos del pecado. Por ello, quizás se aprovecha y agudiza el impacto de la violencia en las familias y el contexto antisocial de las audiencias.

Otro factor que es determinante, en la exposición de este tipo de casos, es la espectacularización del hecho informativo, lo que se observa en determinados programas, pues la televisión sí influye en la temática sobre los que la sociedad discute, incluso con agresividad.

\subsection{Justificación de la investigación, relevancia social}

Considerando esta clasificación, la investigación partió del interés de conocer la visión y percepción de los jóvenes universitarios respecto a la preferencia del dominical "Nunca más", programa de corte periodístico con temática de conflicto familiar y social, difundido por Andina de Radiodifusión, canal 9 o ATV; y de la serie "La rosa de Guadalupe", que presenta dramas que pudieran 
ser factibles en la vida real, vinculados con la solución por intercesión divina, en su versión original (mexicana) y su adaptación peruana, difundidas ambas por América Televisión, Canal 4.

La ONU (2020), en su informe de septiembre de 2020, dio a conocer que, en el mundo, "el 35 por ciento de las mujeres ha experimentado alguna vez violencia física o sexual por parte de una pareja íntima", y que menos del 40 por ciento de las mujeres que experimentan violencia buscan cualquier clase de ayuda.

Si bien son conocidos la crítica y el rechazo a esta manifestación de violencia, es importante conocer de cerca la visión de los jóvenes respecto a la exhibición de la violencia contra la mujer en la televisión y comprobar algún efecto colateral en ellos como hijos, tal como lo señaló Dulanto (2008). Según concluyó el citado autor, "los síntomas de violencia de cualquier tipo entre los progenitores traen como consecuencia un profundo miedo a la vida entre los jóvenes, así como un sentimiento de inseguridad, pérdida de la autoconfianza y un sentimiento de minusvalía".

Respecto al segundo tema, la religiosidad y la fe son aspectos que caracterizan a nuestra sociedad, pues el espíritu religioso ha estado siempre ligado al ser humano. Al respecto, Ramírez (2002) señala que "la conciencia religiosa se exterioriza en diferentes actividades, especialmente las de culto, en las que el sujeto pretende una relación con su objeto, y en modos organizativos, tanto en normas, prohibiciones y regulaciones como en agrupaciones" (p.4).

Además, los jóvenes, como parte de esta sociedad, tienen una visión particular acerca de las manifestaciones religiosas, en razón a que la religión, como todo fenómeno social, se expresa en diversas acciones y, como dijo Hernández (2006), la religión se ha constituido como generadora de sentido de la existencia del ser humano, además de fomentar un sistema simbólico que "imprime concepciones de la existencia muy eficaces en el sentido de solventar respuestas de orden valorativo, y puede ser leída como expresión de las necesidades y pretensiones de sectores sociales, económicos y culturales" (p.200).

Asimismo, es importante conocer lo que los jóvenes, especialmente los que tienen acceso a la educación superior, perciben acerca de la exposición de 
la violencia familiar en un programa de televisión; y sobre el seguimiento permanente y cautivo que tienen aproximadamente 800 mil familias de todos los estratos sociales hacia un programa con un melodrama religioso.

En esa línea, la investigación se orientó además a indagar si el registro de sintonía de los programas con predominio del catolicismo y de conflicto social antes de la COVID-19, se fortaleció en la etapa de la restricción del derecho a circular libremente (toque de queda) desde las 20 horas; y si esa atracción por un programa de contenido religioso influyó en el rating de serie peruana "La rosa de Guadalupe", llamada "Rosita peruana", una adaptación a la realidad nacional de la mexicana.

\subsection{Tiempo de estudio}

Esta investigación se inicia en el mes de junio de 2020, durante una sesión académica virtual, cuando en un receso se consulta a los estudiantes por sus actividades recreativas en familia, y algunos responden que, al no poder salir, ven "la Rosita", y otros, "Nunca más".

Empieza con la búsqueda de información sobre los programas de mayor rating en el periodo de cuarentena, estableciendo el periodo del 15 de marzo al 30 de junio, con contenido religioso y de fenómeno social (violencia intrafamiliar). Se analizaron los resultados de sintonía de ese lapso, registrados por "La rosa de Guadalupe" (original) de lunes a domingo en distintos horarios, la versión peruana de esta serie, que tiene el mismo nombre, y el programa dominical "Nunca más", en comparación con los resultados del rating de 2019 para esos programas dentro del periodo señalado. Esta comparación no aplica a la “Rosita peruana", pues esta se estrenó recién el 19 de marzo de 2020.

\section{Metodología}

Con esta investigación se pretende una aproximación a la percepción de los jóvenes respecto a la preferencia por los contenidos religiosos y de violencia familiar en la televisión. Se trata de una investigación mixta, de enfoque cualitativo, a partir de un estudio estadístico cuantitativo de la audiencia de dos programas televisivos. 
Para ello, se reunió y sistematizó el rating medido por la empresa Kantar Ibope Media en Lima y en las ciudades de Trujillo, Chiclayo, Piura, Huancayo, Arequipa y Cusco, entre el 15 de marzo y el 30 de junio de 2020.

En el análisis de la información se observa la presencia, en los primeros 25 lugares, del total de programas emitidos en televisión nacional (47) de "La rosa de Guadalupe" en diversos horarios, tres veces al día, de lunes a domingo. Igualmente, la emisión del programa dominical de casos de conflicto familiar, "Nunca más", alcanza importantes lugares de preferencia en el público.

Para conocer la percepción de los jóvenes estudiantes, como técnica de averiguación se aplicó una encuesta anónima cerrada con tres preguntas, vinculadas a la estimación del por qué la preferencia de las familias peruanas por los programas "La rosa de Guadalupe" y "Nunca más".

La encuesta fue aplicada a 100 alumnos, de entre 20 y 22 años, de las universidades Jaime Bausate y César Vallejo, ubicadas en Lima Metropolitana, con lugar de residencia es la capital peruana y que trabajan part time para costear sus estudios.

\section{Programas televisivos con contenido religioso}

\section{1. "La rosa de Guadalupe", el programa mexicano original}

"La rosa de Guadalupe" es una producción serial mexicana creada en el año 2007. Empezó a difundirse un año después, emitiendo en cada capítulo temas y problemáticas de actualidad, los cuales convierte en verdaderas historias de lucha y esperanza. Sus historias giran en torno a temas difundidos por los noticieros locales como narcotráfico, drogadicción, trata de personas, violencia, discriminación y bullying. Se le considera un programa de televisión con referencia religiosa guadalupana, donde la imagen central es la Virgen de Guadalupe.

Se inició con un rating de aproximadamente 4,5 millones de espectadores y, durante la pandemia, registró 3,8 millones de personas en la sintonía. Su público son los padres o madres que buscan cómo orientar a sus hijos. Produce 170 capítulos anuales y se exporta a 23 países, entre ellos el Perú, donde se 
trasmite en el rubro de telenovelas. Tiene 13 temporadas y 1440 capítulos emitidos.

Sus productores argumentan que no tiene contenido religioso; ello, no obstante, la regidora del municipio de Gonzales Alonso (como se citó en Vásquez, 2011) cuestionó este tratamiento de los temas con la anuencia de la iglesia católica. Según su análisis, en este programa se detallan de manera explícita sucesos negativos que, en lugar de educar y construir una buena sociedad, fomentan la comisión de ilícitos penales entre los niños y jóvenes; sin embargo, el máximo ícono religioso mexicano manifestará un milagro al final del episodio, por lo que funciona como un catalizador del desenlace.

\subsubsection{Características de "La rosa mexicana"}

En "La rosa mexicana" cada capítulo es autoconclusivo, es decir, que las historias emitidas son de un solo capítulo. Este consta de una introducción, un nudo y un final. Presenta casos a partir de situaciones reales, con actores poco conocidos. Reúne, además, versiones del público y los análisis de los casos sociales y temas de moda, difundidos por los medios de comunicación en todos sus formatos.

Esto ha generado una mayor atención en los jóvenes, sobre todo en los hombres, de acuerdo con los niveles de sintonía. Según New York Times (Kitroeff, 2015), "La rosa de Guadalupe" registró un gran crecimiento de audiencia entre los televidentes masculinos de 13 a 31 años, cuyas cifras aumentaron en aproximadamente un $40 \%$ en comparación con las del año pasado.

El programa, cuyas características se asemejan a las de un melodrama, presenta cinco momentos bien definidos: a) problema, b) ruego o súplica a la Virgen, c) solución/milagro y d) moraleja. La estructura apunta siempre a la solución de un problema, solicitándola a través de alguna petición u oración a la Virgen de Guadalupe. En su desarrollo, este problema debe afectar a los protagonistas para que ellos u algún allegado ore ante la Virgen -cuya imagen o figura está presente en los hogares mexicanos, en un altar junto al ingreso de la casa-, invocando la solución a través del ruego o la súplica. En el desenlace, el "milagro" concedido se evidencia con una cortina musical original, creada especialmente para la serie, mientras la imagen presenta al beneficiario del 
favor que es "bendecido" con una suave corriente de aire, mientras en una mesa del recinto aparece una rosa blanca de la cual se desprende un ligero vaho blanquecino.

\subsubsection{Estructura de un capítulo}

Para el sustento de la indagación, se analizó el capítulo de 43 minutos titulado "Camino de lágrimas", emitido el 19 de diciembre de 2018. Esta estructura puede establecerse de la siguiente manera:

- El problema: el problema principal gira en torno a la historia de un hombre de alto nivel económico que tiene dos familias. Con una de ellas convive en una mansión, de lujo y comodidad, y con la otra hace lo propio en una morada humilde, de evidentes restricciones económicas. En cada una, y con la respectiva pareja, tiene una hija. Luego se presentan cuatro situaciones. En una se observa cómo la mujer pobre, que está enferma y abandonada, decide buscar a su pareja, y, al no encontrarla, decide acudir a la otra pareja en presencia de las dos menores. En este punto, la discusión también involucra a las niñas, por la exclusividad de la paternidad.

En la segunda situación se presenta la crisis familiar a consecuencia del deceso de la señora, pero también del padre, quien, poco antes de morir y arrepentido de su accionar, pide a la hija que goza de recursos económicos que busque y cuide a su hermana, que quedará totalmente desamparada.

Un tercer momento presenta la disputa de ambas hermanas por el amor de un mismo hombre, agresivo y desempleado. La tensión en la primera familia llega al punto en que la hija abandona el hogar. La madre, en su desesperación, acude a centros de diversión nocturna, y en uno de ellos encuentra a la hija de su esposo, que ya huérfana de padre y madre, vive una vida descontrolada. No obstante, la mamá de su hermana deja de lado su orgullo y le pide ayuda para lograr su empresa.

Finalmente, ocurre el hecho trágico. Cuando por fin encuentra a su hermana, la muchacha se enfrenta al individuo que tenía retenida a su hermana, y en medio de una pelea lo acuchillan, ocasionando su muerte. La secuencia termina con la victimaria en prisión. 
- La súplica a la Virgen: al tomar conciencia de la gravedad de los hechos, y la situación en que se encuentra finalmente la hermana defensora, madre e hija deciden ayudar a la inculpada y se muestran arrepentidas de haber abandonado a la muchacha. Luego piden perdón y ayuda para ella ante una imagen de la Virgen de Guadalupe. Inicia entonces el momento cumbre del capítulo, cuando, en una especie de respuesta, aparece el suave viento que roza su rostro con la cortina musical característica de fondo.

- La solución/milagro: el cuadro cambia a la celda de la muchacha, mientras continúa la música $\mathrm{y}$, en medio de un halo de luz, aparece una rosa blanca. Ella la toma, su rostro se ilumina y, como entendiendo el mensaje, promete reencauzar su vida por la senda del bien. Luego, la escena la presenta ya libre $\mathrm{y}$, con la flor en la mano, busca a la madrasta y a su media hermana.

- La enseñanza: luego de cerrar los ojos y de un suspiro, la mujer que sale de la cárcel reflexiona sobre su decisión con una frase: "De ahora en adelante, solo sonrisas y amor. Se acabó el camino de lágrimas". La toma de televisión termina con un abrazo de las tres mujeres. El acompañamiento musical refiere a melodías tristes y dramáticas.

El éxito de estas historias melodramáticas radica ahora en un nuevo plus agregado a su márquetin: el meme, es decir, se imitan y caricaturizan a través de memorias sociales.

\subsection{Estructura de "La rosita peruana"}

Dado su éxito en Latinoamérica, América TV, en el Perú, apostó por una copia de la serie mexicana, es decir, con el mismo esquema, con personajes reconocidos del ambiente artístico nacional. Grabó un primer paquete de 20 capítulos difundidos desde el 20 de marzo hasta el 17 de abril de 2020 . La historia inicial fue la desaparición de una bebé durante un incendio. Las plegarias de la madre a la Virgen de Guadalupe fueron escuchadas y el "milagro" se produce al encontrar a la menor sana y salva.

En la preventa de un año antes, América Televisión (2019) difundió un anuncio de 3'07', en cuyo guion se mostraron imágenes de creyentes de rodillas en súplicas a la Virgen, así como del característico vaho blanco y de 
la rosa blanca, que son aspectos clave de la versión extranjera y el plus que la diferencia de las telenovelas clásicas. El texto que acompaña a las imágenes dice: "A veces la vida nos golpea con mucha fuerza. Cuando la injusticia es insoportable, cuando nuestra voluntad se desvanece, cuando la culpa nos carcome, cuando el miedo nos paraliza, cuando no tenemos a quién acudir, cuando creemos que todo está perdido, siempre habrá una luz".

Para la versión peruana se grabó un tema musical, titulado "Un nuevo día" (Escuchar es práctico, 2020), cuya letra dice lo siguiente:

Al final del camino siempre habrá una esperanza, una luz que ilumina tu alma. Nunca pierdas la fe ni la calma. Cuando sientas que todo anda mal, cuando sientas que el sol no saldrá, siempre existe una salida, una nueva ilusión nace de tu corazón. El amor curará las heridas. La vida es el amanecer de un nuevo día. Llena de esperanzas y alegrías, persigue tus sueños, que todo se hará realidad. No hay miedos que puedan apagar tus sentimientos. Una luz te cuida desde el cielo. Desde el cielo nace una ilusión.

Si bien las historias contadas en la versión peruana son similares a las de su par mexicano, en el primer caso existe un componente adicional: la temática local con mucha presencia del problema del racismo, el maltrato en la familia, el maltrato en las escuelas de docentes hacia los alumnos, las peleas de medios hermanos en hogares disfuncionales, los enfrentamientos entre hermanos, el cuestionamiento de los hijos a los nuevos compromisos de los padres. A diferencia de la serie mexicana, en las grabaciones se incluyó no solo a intérpretes debutantes o poco conocidos, sino también a personajes y artistas reconocidos en la escena local. Asimismo, se utilizó música juvenil variada y de suspenso, situación que no ocurre en su par mexicano. Entre los títulos de los capítulos presentados durante la primera temporada de "La rosita peruana", se encuentran "Emilia sufrirá por las burlas hacia su físico e intentará acabar con su vida", "Paloma fue seducida por su inquilino Moisés", "Horario mantendrá una relación con la mejor amiga de su hija” y "Katia será víctima de los maltratos de su enamorado Alejandro". 


\subsubsection{Estructura de un capítulo}

Para conocer la estructura de la versión peruana, se analizó el capítulo titulado "Emilia sufrirá por las burlas hacia su físico e intentará acabar con su vida" (América Televisión, 2020), emitido el 17 abril de 2020. Esta estructura es la siguiente:

-El problema: el problema principal es el bullying que sufre una mujer desde su niñez y, con mayor fuerza, por parte de sus compañeras de estudios. Frente a esta indiferencia, una compañera decidió hacer la excepción, entregándole como muestra de confianza una figura de la Virgen de Guadalupe. La historia gira, además, sobre otros problemas que afronta la joven acosada, como la burla de la que es objeto, el abandono de las clases y el intento de suicidio, por lo que es llevada al sicólogo. Ya recuperada, citando a La Virgen de Guadalupe, juró ante su madre volver a las clases.

-El ruego o súplica a La Virgen: la madre acude a la Virgen de Guadalupe para lograr que su hija se recupere y consiga su felicidad con un compañero estudiante.

-La solución/milagro: la estudiante, que lleva en la portada de un cuaderno la imagen de la Virgen de Guadalupe, retorna a sus clases y encuentra reciprocidad en el amor en su centro de estudios.

-La enseñanza: la historia culmina con un extenso mensaje acerca de la importancia de que las personas se sientan merecedoras de amor y en la confianza hacia el amor propio.

Al igual que las otras historias peruanas, este tema termina con este tipo de mensaje para generar conciencia en la teleaudiencia y asociarlo con la realidad local. Este capítulo analizado registró 1138000 televidentes en promedio, entre las historias peruanas de "La rosita peruana" emitidas entre el 13 y 19 de abril de 2020. De esta cifra, 877 000, correspondían al rango de 18 a 99 años. Las otras 251000 tenían menos de 18 años, según las cifras de Kantar Ibope Media (2020).

¿Qué factores determinaron tan alta sintonía? ¿Serán los mismos que ocurren con la teleaudiencia afín a la religiosidad en México, considerando 
que los problemas y situaciones sociales son casi los mismos: pobreza, mística religiosa, violencia familiar? ¿Son las enseñanzas que dejan las series de ficción, como dicen Astudillo et al. (2017)? ¿O quizás porque crean conductas supersticiosas ante la resolución de problemas, como recalcó Vásquez (2011)?

\section{Programa de entrevistas de casos sociales: "Nunca más"}

"Nunca más" apareció en televisión en 2011 para difundir, en un formato periodístico, historias de las personas más vulneradas, sobre todo mujeres. Se emite los domingos y su creadora y conductora es la periodista Andrea Llosa Barreto, quien afirma que decidió involucrarse y "comerme el pleito hasta encontrar no sé si un final feliz, pero sí un final justo", según su descripción en una red social.

La televisora indica que el programa "Nunca más" busca presentar casos reales sobre conflictos familiares que aún no tienen solución, pues la esencia del programa es que estos abusos nunca más se cometan. Le da fuerza a su contenido con el eslogan "porque tu historia merece un final justo, nosotros te ayudamos a encontrarlo". Específicamente, trata temas como violencia doméstica, practicada por ambos géneros, juicios por alimentos, infidelidad, disputa por hijos y la paternidad. Un ejemplo es "El engaño del que fue víctima un padre ¿No era su hijo?”, emitido el 20 de junio de 2020. Otro ejemplo es "Hombre desquiciado persigue a expareja ante la cámara de Nunca más", difundido el 28 de junio de 2020.

Debido a que las imágenes que trasmite el programa son violentas, la televisora se cubre de las acciones legales en su contra colocando una claqueta en el inicio de cada edición en la que se indica: "Las escenas de este programa tienen un contenido apto para mayores de 14 años, acompañados de un adulto. Las investigaciones o reportajes incluyen recreaciones de los hechos y no constituyen noticias o hechos difundidos de la realidad actual. Las opiniones, conclusiones e investigaciones son de responsabilidad del productor de la serie". 


\subsection{Estructura de una emisión}

En la emisión titulada "Hombre desquiciado persigue a expareja ante la cámara de Nunca más", la directora y conductora del programa desarrolla la historia del caso durante 66'21'. En la presentación, de 1'48', se revela el nombre de los protagonistas: Lourdes Lizana Gutiérrez y Jesús Antonio Taboada Alama, y da cuenta de una estadística sobre las 45 mil llamadas telefónicas por casos registrados de violencia familiar y de mujeres que fueron violentadas, durante los tres primeros meses de la pandemia. Explica que, a pesar de haber terminado la relación marital de 22 años con el agresor, este amenaza a su víctima con arrancarle la cabeza si la encuentra con otro hombre.

El programa consta además de la siguiente estructura:

- Contexto del caso

Presentación

Antecedentes

- Desarrollo del caso

Entrevista

Reportaje

Entrevista en estudios

- Conclusión

En el contexto, se intercalan los diálogos agresivos con expresiones subidas de tono y amenazas de muerte vertidas por Taboada contra Lizana, haciéndose hincapié en las acusaciones, para lo cual se refuerza con la trascripción instantánea y que se muestra en la pantalla.

En el desarrollo del tema investigado durante cuatro meses, la conductora explica la historia de la violenta relación, la denuncia de la víctima y las medidas de protección dictadas por un juez, que no se cumplen. Entrevista además en estudios a la denunciante, quien relata su caso entre llantos y muestra los audios con las amenazas de muerte que le hace el agresor vía WhatsApp y un seguimiento en motocicleta. La conductora también usa calificativos contra Taboada, quien temerariamente trata de colisionar al automóvil del equipo periodístico en el que viaja Lizana. 
En la conclusión, Llosa entrevista a un jefe policial, quien confirma la detención del agresor y se compromete a brindarle garantías a la denunciante. Además, un abogado se ofrece para hacerle el seguimiento al encarcelamiento al detenido y, finalmente, una psicóloga ofrece su servicio para el tratamiento de la víctima y sus hijos.

\section{Trabajo de análisis}

\subsection{Medición de sintonía: ranking durante la semana}

Gracias a la tecnología, en la actualidad es factible conocer el movimiento de los controles de la televisión, especialmente en seis ciudades del país, donde la empresa Kantar Ibope Media tiene instalados audímetros de medición de sintonía, conocidos como "People Meter". Este sistema registra hogares y personas.

La función que cumple el audímetro es rastrear minuto a minuto el uso de la televisión en la vivienda donde está instalado. Lo hace de manera grupal o individual, siempre y cuando cada una de las personas tenga un código de acceso. Si se cambia de canal, automáticamente queda registrado en el sistema, de donde es extraído de manera virtual por la operadora.

Para conocer la preferencia y cantidad de seguidores que registró "La rosa de Guadalupe" en sus versiones peruana y mexicana, emitidas por América TV; así como "Nunca más", que se emite por ATV, en tanto a los índices de audiencia semanal y dominical, se presentará la ubicación de los dos formatos desde el 16 de marzo hasta el 30 de junio de 2020, de acuerdo con la información de Kantar, en una versión adaptada de la clasificación.

Para la comprensión de las tablas que se presentan, es preciso señalar que el rating analizado está clasificado de la siguiente manera: a) en miles de personas, b) miles de hogares, c) miles de amas de casa y d) miles de personas de 18 a 99 años en Lima y seis ciudades del interior.

En las tablas siguientes se presenta la ubicación de las emisiones de "La rosa de Guadalupe" versión peruana, en su horario de lunes a viernes, de 9:15 a 10:00 p. m., que se identifica como "N" (de noche), desde su estreno hasta completar los 20 capítulos del ciclo. "La rosa de Guadalupe", la original 
mexicana, es registrada en diversas emisiones que alcanzan ubicación entre los primeros 25 lugares del rating. De lunes a viernes, dos emisiones entre las 6:00 y las 7:30 p.m., que se identifican como " $T$ " (tarde) la primera y "T1" (tarde 1) la segunda; los sábados, dos emisiones entre las 6:30 y 8:00 p.m., que se signan como "ST" (sábado tarde) y "SN" (sábado noche); y los domingos, entre las 6:00 y 7:00 p.m., que están identificadas como "DT" (domingo tarde) y "DN" (domingo noche), respectivamente. Cuando culmina la emisión peruana, la versión mexicana original ocupa su lugar de lunes a viernes en la noche $(\mathrm{N})$. Las emisiones matinales no fueron consideradas por no haber ingresado al top registrado.

En la semana del 16 al 22 de marzo (semana de estreno), que coincide con el inicio de la cuarentena, la versión peruana de "La rosa de Guadalupe" se ubicó en primer lugar, con casi un millón y medio de televidentes en su primer capítulo. La versión mexicana ocupó los puestos 7, 8, 10, 14, 23 y 24 en sus distintos horarios. De 1403000 personas que sintonizaron la emisión peruana de "La rosa de Guadalupe" el viernes 20 de marzo de 2020, 1050000 fueron personas cuyas edades oscilan entre los 18 y 99 años, en 827 mil hogares; además, del total de televidentes, 428000 fueron amas de casa. El resto (353 000) fueron menores de 18 años. Las otras seis emisiones semanales de la versión mexicana, aunque no llegan a los primeros lugares, se ubican dentro de los 25 programas más vistos. En este rango no aparece "Nunca más", porque el domingo 22 no logró ubicarse entre los primeros 25 lugares de sintonía (Tabla 1).

\section{Tabla 1}

Rating de la semana del 16 al 22 de marzo 2020

\begin{tabular}{clrrrr}
\hline Ubic. & \multicolumn{1}{c}{ Programa } & Personas & Hogares & A. casa & May.18 \\
\hline 1 & $\begin{array}{l}\text { La rosa de Guadalupe } \\
\text { (versión peruana) }\end{array}$ & 1403 & 827 & 428 & 1,050 \\
7 & La rosa de Guadalupe ST & 968 & 613 & 336 & 732 \\
8 & La rosa de Guadalupe SN & 925 & 610 & 335 & 742 \\
10 & La rosa de Guadalupe T & 909 & 592 & 322 & 704 \\
14 & La rosa de Guadalupe T1 & 811 & 513 & 280 & 618 \\
23 & La rosa de Guadalupe DT & 690 & 449 & 231 & 510 \\
24 & La rosa de Guadalupe DN & 679 & 444 & 216 & 536 \\
\hline
\end{tabular}

Nota: Kantar Ibope Media (2020). 
En la semana del 23 al 29 de marzo, "La rosa de Guadalupe" ocupó seis de los 25 primeros puestos de los programas más vistos en la semana, y la versión peruana alcanzó 1242000 personas frente al televisor, en 737000 hogares, manteniendo el primer lugar en su emisión, aunque con 151000 televidentes menos que en su debut. En ese rango de fechas, "Nunca más", emitido el domingo a las 8:30 de la noche, logró sintonía de 1060000 televidentes en 652000 hogares. En el público de "Nunca más" hubo 844000 personas cuyas edades oscilan entre los 18 y 99 años, y también menores de edad, unos 156 000 (Tabla 2).

\section{Tabla 2}

Rating de la semana del 23 al 29 de marzo de 2020

\begin{tabular}{clrrrr}
\hline Ubic. & \multicolumn{1}{c}{ Programa } & Personas & Hogares & A. casa & May. 18 \\
\hline 1 & $\begin{array}{c}\text { La rosa de Guadalupe } \\
\text { (versión peruana) }\end{array}$ & $1242^{*}$ & 737 & 419 & 943 \\
3 & La rosa de Guadalupe N & 1220 & 748 & 401 & 912 \\
6 & La rosa de GuadalupeN1 & 1067 & 690 & 369 & 822 \\
7 & Nunca más & 1060 & 652 & 311 & 844 \\
9 & La rosa de Guadalupe N & 958 & 617 & 364 & 824 \\
10 & La rosa de Guadalupe T1 & 908 & 550 & 324 & 734 \\
25 & La rosa de Guadalupe T & 892 & 555 & 337 & 739 \\
\hline
\end{tabular}

Nota: Kantar Ibope Media (2020).

En las siguientes semanas, la sintonía de "La rosa de Guadalupe" baja al segundo, tercer y hasta cuarto lugar, superada por la comedia "Los Vílchez", aunque sus emisiones en sus horarios vespertinos y nocturnos de lunes a domingos se mantienen entre los 25 programas más vistos. "Nunca más", en la tercera semana de cuarentena, bajó en más de 200000 televidentes con relación a la semana anterior. No obstante, en las siguientes semanas del estudio se observó una importante ubicación, en el tercer lugar, y en el sexto y sétimo, de acuerdo con el tema presentado, como se verá en detalle más adelante (Tabla 3). 


\section{Tabla 3}

Rating de la semana del 16 al 22 de marzo 2020

\begin{tabular}{|c|c|c|c|c|c|}
\hline Ubic. & Programa & Personas & Hogares & A. casa & May.18 \\
\hline \multicolumn{6}{|c|}{ Del 30 de marzo al 5 de abril } \\
\hline 2 & $\begin{array}{l}\text { La rosa de Guadalupe } \\
\text { (versión peruana) }\end{array}$ & $1260^{\star}$ & 755 & 419 & 957 \\
\hline 25 & Nunca más & 688 & 437 & 263 & 612 \\
\hline \multicolumn{6}{|c|}{ Del 6 al 12 de abril } \\
\hline 3 & La rosa de Guadalupe N & $1414^{\star *}$ & 817 & 499 & 1,090 \\
\hline \multicolumn{6}{|c|}{ Del 13 al 19 de abril } \\
\hline 2 & La rosa de Guadalupe N & $1138^{*}$ & 675 & 382 & 877 \\
\hline 7 & Nunca más & 816 & 488 & 302 & 658 \\
\hline
\end{tabular}

Del 20 al 26 de abril

$\begin{array}{llrrrr}4 & \text { La rosa de Guadalupe N } & 1104 & 668 & 394 & 876 \\ 6 & \text { Nunca más } & 877 & 515 & 332 & 670\end{array}$

Del 27 de abril al 3 de mayo

4 La rosa de Guadalupe N

6 Nunca más

6229

376

824

474

284

649

Del 4 al 10 de mayo

3 La rosa de Guadalupe N

1076

679

387

849

13 Nunca más

675

434

228

541

Del 11 al 17 de mayo

3 La rosa de Guadalupe SN

$1017^{\star}$
712

11 Nunca más

712

Del 18 al 24 de mayo

3 La rosa de Guadalupe N

$939^{*}$

$4 \quad$ Nunca más

843

Del 1 al 7 de junio

3 La rosa de Guadalupe N

994

7 Nunca más

760

$632 \quad 360$

786

445

242

600

Del 8 al 14 de junio

4 La rosa de Guadalupe N

931

23 Nunca más

514

590

330

715

506

309

700

\section{Del 15 al 21 de junio}

3 La rosa de Guadalupe-N1

1003

584

14 Nunca más

66

458

762

627

$\begin{array}{lll}458 & 286 & 627\end{array}$

$\begin{array}{lll}635 & 326 & 668\end{array}$

$357 \quad 213 \quad 424$

$628 \quad 319 \quad 713$

$363 \quad 210 \quad 471$


Del 22 al 28 de junio 2020

\begin{tabular}{clllll}
4 & La rosa de Guadalupe-NO & 886 & 586 & 312 & 638 \\
10 & Nunca más & 662 & 406 & 251 & 547 \\
\hline
\end{tabular}

Nota: Kantar Ibope Media (2020).

\subsection{Medición de sintonía: ranking dominical}

En el registro dominical, ambos programas cambian de ubicación entre los 25 más vistos en esas 24 horas, porque al tratarse de un día familiar y de descanso, en la parrilla se difunden formatos con entretenimiento, como películas en señal abierta. Además, es el día de mayor consumo de canales de televisión en streaming.

En el análisis de la programación realizado desde el 15 de marzo hasta el 28 de junio, el monitoreo arrojó que, de los 15 domingos evaluados, "Nunca más" tuvo una sintonía mayor con relación a la serie mexicana, incluso el 29 de marzo de 2020 llegó a las 892000 personas en sintonía, como se puede apreciar en la Tabla 4.

El día del más alto rating se presentó el caso de un padre de familia amenazado de muerte por su esposa, de la que se separó hace cinco años. La pareja tiene tres hijos y él cría a dos de ellos.

\section{Tabla 4}

Domingos de marzo, 2020

\begin{tabular}{|c|c|c|c|c|c|c|}
\hline & Ubic. & Programa & Personas & Hogares & $\begin{array}{c}\text { Amas } \\
\text { de casa }\end{array}$ & $\begin{array}{c}\text { Mayores } \\
\text { de } 18\end{array}$ \\
\hline $\begin{array}{l}\text { Dom. } \\
15\end{array}$ & 2 & La rosa de Guadalupe $\mathrm{T}$ & 547 & 412 & 201 & 417 \\
\hline \multirow{2}{*}{$\begin{array}{l}\text { Dom. } \\
22\end{array}$} & 5 & Nunca más & 493 & 307 & 149 & 390 \\
\hline & 7 & La rosa Guadalupe T & 613 & 381 & 209 & 434 \\
\hline \multirow{2}{*}{$\begin{array}{l}\text { Dom. } \\
29\end{array}$} & 2 & Nunca más & $892^{*}$ & 555 & 337 & 739 \\
\hline & 5 & La rosa de Guadalupe T & 633 & 415 & 223 & 500 \\
\hline
\end{tabular}

Nota: Kantar Ibope Media (2020). 


\section{Tabla 5}

Domingos de abril, 2020

\begin{tabular}{|c|c|c|c|c|c|c|}
\hline & Ubic. & Programa & Personas & Hogares & $\begin{array}{c}\text { Amas de } \\
\text { casa }\end{array}$ & $\begin{array}{c}\text { Mayores } \\
\text { de } 18\end{array}$ \\
\hline Dom. & 5 & La rosa de Guadalupe DT & 728 & 471 & 256 & 607 \\
\hline 5 & 3 & Nunca Más & 688 & 437 & 262 & 612 \\
\hline Dom. & 3 & La rosa de Guadalupe & 828 & 566 & 296 & 642 \\
\hline 12 & 5 & Nunca Más & 703 & 407 & 238 & 598 \\
\hline Dom. & 1 & Nunca Más & 816 & 488 & 302 & 658 \\
\hline 19 & 8 & La rosa de Guadalupe & 573 & 377 & 203 & 446 \\
\hline Dom. & 1 & Nunca Más & 877 & 515 & 332 & 670 \\
\hline 26 & 10 & La rosa de Guadalupe & 531 & 343 & 186 & 393 \\
\hline
\end{tabular}

Nota: Kantar Ibope Media (2020).

\section{Tabla 6}

Domingos de mayo, 2020

\begin{tabular}{lclcccc} 
& Ubic. & \multicolumn{1}{c}{ Programa } & Personas & Hogares & $\begin{array}{c}\text { Amas de } \\
\text { casa }\end{array}$ & $\begin{array}{c}\text { Mayores } \\
\text { de 18 }\end{array}$ \\
\hline Dom. & 1 & Nunca Más & 799 & 474 & 284 & 649 \\
3 & 8 & La rosa de Guadalupe & 579 & 384 & 194 & 450 \\
Dom. & 2 & Nunca Más & 675 & 434 & 228 & 541 \\
10 & 8 & La rosa de Guadalupe & 515 & 310 & 165 & 365 \\
Dom. & 2 & Nunca Más & 712 & 445 & 242 & 600 \\
17 & 5 & La rosa de Guadalupe & 636 & 402 & 203 & 489 \\
Dom. & 1 & Nunca Más & 843 & 506 & 309 & 700 \\
24 & 8 & La rosa de Guadalupe & 523 & 362 & 161 & 350 \\
\hline
\end{tabular}

Nota: Kantar Ibope Media (2020).

\section{Tabla 7}

Domingos de junio, 2020

\begin{tabular}{lclcccc}
\hline & Ubic. & \multicolumn{1}{c}{ Programa } & Personas & Hogares & $\begin{array}{c}\text { Amas de } \\
\text { casa }\end{array}$ & $\begin{array}{c}\text { Mayores } \\
\text { de } 18\end{array}$ \\
\hline Dom. & 1 & Nunca Más & 760 & 458 & 286 & 627 \\
7 & 6 & La rosa de Guadalupe & 539 & 325 & 172 & 395 \\
Dom. & 4 & La rosa de Guadalupe & 542 & 377 & 179 & 408 \\
14 & 5 & Nunca Más & 514 & 357 & 213 & 424 \\
Dom. & 1 & La rosa de Guadalupe & 673 & 420 & 198 & 497 \\
21 & 2 & Nunca Más & 584 & 363 & 210 & 471 \\
Dom. & 1 & Nunca Más & 662 & 406 & 251 & 547 \\
28 & 12 & La rosa de Guadalupe & 395 & 337 & 152 & 305 \\
\hline
\end{tabular}

Nota: Kantar Ibope Media (2020). 


\subsection{Encuesta de percepción de los jóvenes universitarios}

Los jóvenes son seguidores de la televisión, pues en ella ven patrones de conducta similares a los suyos o aspiracionales y, como dice Cortavidarte (2016), "los modelos que los jóvenes emplean como referencia pueden provenir del ámbito familiar, padres y abuelos, como también de sus pares y, cada vez en mayor medida, en la exploración tecnocultural que hacen de la imagen y la sonoridad" (p.38), apreciada en la televisión.

En un contexto particular y único, no vivido en el último siglo, y frente a la alta sintonía de estos programas, se aplicó un cuestionario a 100 estudiantes de las universidades Jaime Bausate y Meza y César Vallejo, con las siguientes preguntas establecidas:

- Pregunta 1: ¿Por qué cree usted que las familias peruanas tienen como programas referentes en la televisión a "La rosa de Guadalupe" y a "Nunca más"?

- Pregunta 2: ¿Es la TV un medio de comunicación influyente en los patrones de comportamiento social?

- Pregunta 3: ¿Por qué cree que un joven prefiere sintonizar los programas "La rosa de Guadalupe" y "Nunca más"?

Con ello se buscó conocer si, además de interesarse por los patrones de exploración cultural y de aquella imagen cotidiana que se aprecia en la pantalla chica, los jóvenes universitarios tenían otra apreciación sobre el por qué sigue primando el interés de la teleaudiencia por programas con contenido social y religioso.

\section{Resultados}

- A la pregunta 1, el 43,8\% respondió que los programas son referentes porque reflejan los problemas de la sociedad y el comportamiento en los hogares; es decir, la crisis familiar, la crisis de valores, la pobreza, los problemas sociales, corrupción, etcétera. El 33,8\% considera que es referente porque refleja, en parte, a nuestra sociedad y sus conflictos. El $12,5 \%$ estima que es referente por su contenido religioso. El 9.9\% considera que los programas son referentes por la idiosincrasia del público. 
- A la pregunta 2, el $48.6 \%$ respondió que la televisión es el medio más influyente en la sociedad; ello debido a su gran fuerza expresiva para trasmitir los patrones de comportamiento social. El 39,7\% considera que el grupo que ve la serie religiosa tiene la convicción de que, en efecto, puede ocurrir un milagro como consecuencia de una plegaria. El 11,7\% refirió que muchas personas han aumentado su fe después de ver los capítulos.

- A la pregunta 3, el 41,4\% dijo que los jóvenes televidentes de la serie mexicana la prefieren porque están convencidos de los milagros divinos. El 37,8\% estima que los seguidores piensan que la Virgen de Guadalupe es el ícono de la religiosidad. El 20,8\% dijo que los jóvenes la ven porque se sienten identificados con los casos sociales y conflictos familiares que se trasmiten en las series.

\section{Discusión}

\subsection{El catolicismo y la influencia de "La Lupita"}

En cuanto al catolicismo, las cifras en México y Perú se mantienen superiores al $75 \%$ de la población, lo que se evidencia en la fe que se profesa masivamente a la Virgen de Guadalupe y al Señor de los Milagros, respectivamente. En México, a inicios del siglo XX, el 99,1\% de los habitantes eran católicos; en 2015, la cifra bajó al $85 \%$ y, en enero de 2020, un censo determinó que, de 126185390 habitantes, la Iglesia Católica aglutina alrededor del 80 \% de la población (Aguilar,2020).

Las cifras revelan que, a pesar de la pérdida de fieles, se mantiene una feligresía compacta hacía una imagen conocida como "La Lupita", y estos devotos, además de los comerciantes, son los principales propulsores de su festividad y de los "milagros" concedidos, lo que es aprovechado por la producción televisiva mexicana como insumo para las emisiones, y para recrear las historias que cuentan sus seguidores.

Y son estas historias las que llegan a los países de habla hispana, entre ellos el Perú, desplazando a las leyendas sobre "milagros" concedidos por las advocaciones regionales, como la Virgen de Suyapa en Honduras, la Virgen 
de Luján en Argentina, la Virgen de Chiquinquirá de Colombia, la Virgen de la Caridad del Cobre de Cuba, entre otras.

En el Perú, la Iglesia Católica es una de las instituciones con mayor influencia en la sociedad desde la época de la Colonia y, aunque se tienen santos y representaciones religiosas que participan activamente en la cultura con testimonios de sus milagros, la Virgen de Guadalupe ha logrado un sitial dentro de esta feligresía.

La cifra de feligresía católica en el Perú disminuye anualmente. Por ejemplo, de acuerdo con el censo de 1940, el 98,51\% de la población era católica. En el año 2017, a raíz de la visita del Papa Francisco a Lima, un sondeo del Instituto de Opinión Pública de la PUCP comprobó que el 89,1\% de peruanos encuestados se reconocían creyentes, de los cuales $75,2 \%$ se declaraban católicos.

Es de anotar que esta cifra bajó casi tres puntos con relación al estudio que hizo en el año 2015 la encuestadora Vox Populi para la Facultad de Teología Pontificia y Civil de Lima. El documento concluyó que la cifra de católicos fue de $78 \%$. El $20 \%$ dijo ser evangélico.

Respecto a las manifestaciones religiosas peruanas, cada región expresa preferencias distintas, a las vírgenes del Carmen, de Cocharcas, del Río, de las Mercedes, del Agua, de la Puerta, entre otras; pero ningún testimonio de favor concedido por ellas ha sido recogido e interpretado en historias, como ha ocurrido con "La Lupita".

El Perú tiene además algunos íconos propios, como San Martín de Porres, el Señor de los Milagros, la Cruz de Motupe, el Señor de Muruhuay, el Señor Cautivo de Ayabaca y el Cautivo de Monsefú, el Señor de Cachuy, y beatas no canonizadas, como la de Humay, Melchorita, Rosita de Pachacámac, así como Sarita Colonia, llamada "Patrona de los pobres".

En el tiempo analizado, el número más alto de sintonía lo registró entre el 23 y 29 de marzo, con 1060000 seguidores en 652000 hogares. De esta cifra, 311 mil fueron amas de casa, según los registros de la encuestadora Kantar Ibope Media. 


\subsection{La percepción de los jóvenes}

De la encuesta aplicada, se obtuvo que los jóvenes consideran que, en ambos programas, los de corte religioso y de contenido familiar, la vida privada de las personas se ha convertido en parte de la parrilla televisiva; pero, además, observan que la sociedad peruana no es ajena al cambio de la época y sigue los modelos de los grupos sociales del exterior. En ese sentido, no llama la atención que la vida familiar sea vista ahora como espectáculo. Por ello, cabe la pregunta si este resultado tiene relación con el 64\% de mujeres mexicanas que manifestaron que les gusta ver este tipo de programas porque, al comprobar que otras personas tienen tantos problemas y sufren tanto con sus conflictos, los problemas que ellas mismas o sus familias tienen les parecen poca cosa (Gamboa, 2001, p.8).

Los jóvenes consideran también que la televisión es el medio más influyente en la sociedad; ello, debido a su gran fuerza expresiva para trasmitir los patrones de comportamiento social. Además, advierten que el grupo que ve la serie religiosa tiene la convicción de que, en efecto, puede ocurrir un milagro como consecuencia de una plegaria. Al respecto, la historia religiosa tiene muchos casos registrados y, en el caso de la Virgen de Guadalupe, esto se da desde el asentamiento español, con la detención de inundaciones y plagas en México, en 1736.

En relación con las denuncias que hacen las víctimas en "Nunca más", refieren que estos casos son comunes en los hogares; es decir, que son "reales" y que la televisión muestra la realidad. Sin embargo, consideran también que mostrar estos casos en televisión nacional puede influir en el aumento de la violencia.

Esta respuesta está relacionada con la Teoría del Cultivo, de George Gerbner, en el sentido de que en la sociedad existe una similitud en las percepciones que pueden ser compartidas y similares en la realidad social del individuo. Pero no solo eso. Según su análisis, si a través de los medios de comunicación se difunden contenidos negativos, la sociedad se volverá cada vez más ávida de malas noticias y, frente a ello, tendrá la percepción de que esto nunca va a cambiar, como señala Bernal (2018).

Sobre la exhibición de casos familiares específicos y reales en "Nunca más", la respuesta confirma los estudios sobre el patrón de comportamiento agresivo 
que muestra la población de manera constante. Ya en 1977, un estudio realizado en Estados Unidos reveló que el 43\% de los adultos encuestados pensaba que la excesiva presencia de programas televisivos, de tipo violento, influiría de alguna manera en que la sociedad sea cada vez más violenta.

Respecto al pronunciamiento sobre los milagros divinos, una de las características del catolicismo latinoamericano es la concepción de la intervención divina en la vida diaria de las personas a través de los milagros. Por tanto, está muy arraigada la manifestación popular sobre estos eventos considerados como acciones divinas y sin explicación científica.

Forero (2018) comprobó que "el fenómeno que se interpreta como milagroso existe en la medida en que se acepte la existencia de una voluntad supranatural que se interpreta como agente con la capacidad de influir en el curso ordinario de la vida" (p.18). En consecuencia, estos hechos seguirán reconociéndose en el catolicismo como lo hace México desde 1531, al hacerse público el milagro concedido por la Virgen de Guadalupe a favor de un indígena que fue sanado de una enfermedad mortal para la época.

El Perú es un país multicultural, pluriétnico, megadiverso y su idiosincrasia está marcada por su cultura, costumbres, comportamiento, valores, conducta y actitudes que delinean la forma de ser peruano. Trathemberg (2008), al analizar el currículo oculto en la educación, añadió tres componentes a la idiosincrasia peruana: incapacidad de reconocer errores, actitud sumisa pasivo-agresiva y asumir que el profesor o la autoridad que tiene el poder siempre tiene la razón.

Como señala Casado (2005), este resultado nos permite confirmar que la televisión es la causante de los comportamientos sociales y modelos de vida a seguir, mayormente contravalores después de la propia vida. De acuerdo con Ferrés \& Roca (1997), estos resultados permiten confirmar el carácter mítico y la fuerza casi religiosa que tiene la televisión en las sociedades occidentales.

A este estudio se pueden agregar los resultados de una encuesta de la Compañía Peruana de Estudios de Mercados y Opinión Pública (CPI) sobre las características de los peruanos: chismosos (84\%), egoístas (78\%), hipócritas (77\%), resentidos $(76 \%)$, violentos $(76 \%)$, envidiosos $(76 \%)$, incumplidos 
(76\%). La encuesta se realizó del 23 de mayo al 8 de junio de 2014, a 2200 personas de 19 regiones del país, incluidos Lima y el Callao. Refleja, sin duda, la realidad peruana.

En el registro televisivo semanal en el que se consideró a la versión peruana de "La rosa de Guadalupe", quedó demostrado que este tipo de formato donde se dramatizan los casos de personas comunes que "experimentan un milagro"- alcanzó un amplio posicionamiento en la parrilla televisiva. Ello, por la presentación sistemática de historias sociales con una mezcla de religiosidad y misterios de la naturaleza. Hay, además, un marcado sesgo con relación a los estratos sociales y de agresión de mujer a mujer; y de racismo acendrado, como el caso de la nuera que, de manera despectiva y con violencia verbal, arroja de su casa a su suegra, diciéndole que regrese a su tierra en la sierra o se albergue en un asilo.

Estas cifras de sintonía son mayores a las que registraron ambos programas en las tres primeras semanas de los meses de abril, mayo y junio de 2019, las cuales revelan que "La rosa de Guadalupe" registró entre 465000 y 666000 seguidores, mientras que "Nunca más" entre 312000 y 318000 televidentes.

El análisis demostró, además, que ambos programas tienen un público cautivo. Por ejemplo, "Nunca más" supera los 500000 televidentes semanales y, "la Rosa mexicana", los 600 000, considerando que la producción azteca se emite diariamente en la televisión peruana. Es, también, ese público cautivo el que les permite generar una porción de la torta publicitaria. Muestra de ello es la cifra de más de un millón de personas que vieron el primer capítulo de "la Rosita peruana"; o el casi millón y medio que vio la versión peruana en la tercera semana de trasmisión. De esa cifra, más de un millón eran mayores de 18 años.

En efecto, el televidente de estos programas "se ve reflejado" en los protagonistas de la historia; cree, además, que siguiendo este patrón de manifestación religiosa, encontrará en la oración, la alabanza o la ofrenda, el milagro anhelado o el rencauzamiento de su vida conforme a la voluntad de la Virgen de Guadalupe, lo que demuestra un marcado cultivo religioso popular del catolicismo presente en Latinoamérica desde la conquista española. 


\section{Conclusiones}

La consulta universitaria y el registro de sintonía de ambos programas son evidencias de que la televisión es el medio más influyente para la difusión de los patrones sociales, por su presencia hegemónica en los hogares y por su gran fuerza expresiva para trasmitir mensajes de la vida cotidiana.

El formato religioso y el de conflicto sociofamiliar tiene éxito en la producción televisiva de México y del Perú porque en ambos se refleja lo que acontece en la vida diaria de un gran sector de ambas sociedades.

Los estudiantes perciben que es clara la preferencia del público por contenidos de violencia familiar o social por su parecido con la realidad. Frente a una gran variedad de alternativas para consumo televisivo, y el tiempo libre para acceder a otros contenidos en tiempos de cuarentena, el televidente ha demostrado su predilección por este tipo de historias.

El alto nivel de sintonía de "La rosa de Guadalupe" en su versiones mexicana y peruana demuestra las coincidencias en la cultura de los públicos peruano y mexicano. En ambos países se evidencia la fe religiosa, con primacía del catolicismo, pero también los factores de pobreza económica, la crisis familiar, la violencia doméstica y los patrones de conducta. Ambas sociedades se identifican con las propuestas cognitiva y socioafectiva que nos brinda la televisión.

En este formato de la televisión narrativa, y en la temática, hay un reconocimiento a la idiosincrasia y a los contextos regionales, sin dejar de lado la violencia practicada por ambos géneros.

La televisión, en tanto espectáculo, recoge la realidad y propicia la identificación con la cultura local, consiguiendo una variedad de espectadores de distintas edades y estratos sociales. 


\section{Fuentes consultadas}

Aguilar, R. (2020, enero 16). Católicos en México. https://www. eleconomista.com.mx/opinion/Catolicos-en-Mexico-20200116-0102. html

América Televisión (2018, noviembre 30). La rosa de Guadalupe Perú [Video]. YouTube. https://www.youtube.com/ watch? $\mathrm{v}=0 \mathrm{oBjsBoFPWU}$

América Televisión (2020, abril 20). La Rosa Perú: Emilia sufrirá por las burlas hacia su físico e intentará acabar con su vida [Video]. YouTube. https://www.youtube.com/watch?v=wPHZQzQeZ_0

Astudillo, E., Núñez, V. y Rodríguez, C. (2017). Consumo televisivo de audiencias infantiles: un estudio cualitativo con estudiantes chilenos-Chile.Comuni@cción, 8(2), 105-115. http://www.scielo. org.pe/pdf/comunica/v8n2/a04v8n2.pdf

Bernal, C. (2018). La noticia policial televisiva y su influencia en la percepción de la cultura de violencia en los estudiantes de periodismo de Universidad San Martín de Porres y Alas Peruanas, Lima [Tesis de maestría, Universidad de San Martín de Porres]. Archivo digital Universidad San Martín de Porres.

Bourdieu, P. (2000). La Dominación Masculina. Anagrama.

Casado, F. (2005). La realidad televisiva como modelo de comportamiento social: una propuesta didáctica. Comunicar: revista Científica de Comunicación y Educación, (2)25, 362363. https://doi.org/10.3916/comunicar

Concortv. (11 de enero de 2018). "La diversidad cultural en la televisión peruana”. http://www.concortv.gob.pe/destacados/la-diversidadcultural-en-la-television-peruana/ 
Concortv. (18 de julio de 2016). SNRTV sanciona a ATV por infringir el Horario Familiar en el programa "Nunca Más". http://www.concortv. gob.pe/noticias/snrtv-sanciona-atv-por-infringir-el-horario-familiaren-el-programa-nunca-mas/

Cortavidarte, E. (2016). Reflexionando sobre la influencia de la televisión en adolescentes y jóvenes limeños: una propuesta de activismo digital [Tesis de maestría, Pontificia Universidad Católica del Perú]. Archivo digital, Pontificia Universidad Católica del Perú.

Dávalos, O. (11 de febrero de 2020). Si nos critican es que nos ven: productor de "La rosa de Guadalupe". Notimex. https://www. masnoticias.mx/si-nos-critican-es-que-nos-ven-productor-de-la-rosade-guadalupe/

Diario Perú 21. (21 de noviembre de 2018). Peruanos dedican diariamente un promedio de 3 horas y 18 minutos a la televisión. Perú 21. https:// peru21.pe/tecnologia/peruanos-dedican-diariamente-promedio-3horas-18-minutos-television-441784-noticia/

Diario El Comercio. (29 de enero de 2020). Kantar: peruanos elevan el consumo de TV durante cuarentena y lideran métricas de la región. El Comercio. https://elcomercio.pe/economia/dia-1/ television-kantar-peruanos-elevan-el-consumo-de-tv-durantecuarentena-y-lideran-metricas-de-la-region-cuarentena-noticia/

Dulanto, E. (2008). Los niños y los jóvenes ante la violencia familiar. Instituto Nacional de Pediatría.

Escuchar es práctico (2020, abril 19). Un nuevo día [Video]. YouTube. https://www.youtube.com/watch?v=hbdrRqbLiSc

Espinoza, J. (2018). Catolicismo, espacio público y cultura en el Perú contemporáneo: Claves históricas para una agenda de investigación. Argumentos, (1), 14-24. http://argumentos-historico. iep.org.pe/wp-content/uploads/2018/09/Espinoza-JM.-2018Catolicismo-espacio-p\%c3\%babico-y-cultura-en-el-Per\%c3\%bacontempor $\%$ c3\%alneo.pdf 
Facultad de Teología Pontificia Civil de Lima (2015). Informe de encuesta nacional urbana y rural encuesta sobre la iglesia católica en el Perú urbano y rural. Vox Populi. Comunicación y Marketing.

Ferrés, J. y Roca, N. (1997). Creencias populares sobre los efectos de la televisión. Universidad Pompeu Fabra y Universidad de Barcelona.

Forero, S. (2018). La razón del milagro catolicismo popular y lógica subjetivista en la devoción a Santa Marta [Tesis de licenciatura, Universidad Javeriana]. https://repository.javeriana.edu.co/ handle/10554/35533

Fraça, L. (2000). La contribución de las series juveniles de televisión a la formación de la identidad en la adolescencia. Análisis del contenido y de la recepción de la serie "Compañeros" de Antena 3 [Tesis doctoral, Universidad Autónoma de Barcelona]. https://www.tdx.cat/bitstream/handle/10803/4092/mefr1de1. pdf? sequence $=1 \&$ is Allowed $=\mathrm{y}$

Gamboa, C. (2001). La mujer, en los talk shows. Revista Latina de Comunicación Social, (4)42. http://www.revistalatinacs.org/2001/ latina42jun/41gamboa.htm

Garcés, B. (2015). Virgen de Guadalupe como imagen de la identidad latinoamericana y sus nuevas lógicas de consumo. Resistencia, 4, 58-61. http://repositorio.uasb.edu.ec/bitstream/10644/4372/1/14-TCGarces.pdf

García, D. (17 de julio de 2017). La rosa de Guadalupe celebra mil capítulos: "La rosa de Guadalupe" aborda temas y problemáticas de actualidad, convirtiéndolas en verdaderas historias de lucha y esperanza. La Voz de Arizona.com. https://amp.lavozarizona.com/ $\operatorname{amp} / 470335001$

González-Anleo, J. (2007). Sentidos y creencias religiosas de los jóvenes españoles. Bordón, revista de pedagogía, 58(4y5), 477-492. https://recyt.fecyt.es/index.php/BORDON/article/view/39578/22308 
Hernández, H. (2006). La religión en la sociedad peruana contemporánea [Archivo PDF] http://www.desco.org.pe/recursos/site/files/ CONTENIDO/9/07PeruHoy20006B.pdf

Lázaro Altamirano, S. (2014). Algunas representaciones sociales contenidas en los rezos del programa de televisión La Rosa de Guadalupe. Caleidoscopio. Revista Semestral de Ciencias Sociales y Humanidades, 17(30), 139-168. https://doi. org/10.33064/30crscsh524

MIMPV (2011). Pautas para el Tratamiento Informativo Adecuado de la Violencia Contra la Mujer en los medios de comunicación social. https://www.mimp.gob.pe/files/programas_nacionales/pncvfs/ pautasparaeltratamiento.pdf

Kitroeff, N. (10 de agosto de 2020). Menos sexo, más audiencia: la pandemia reanima a las telenovelas mexicanas. New York Times. https:// www.nytimes.com/es/2020/08/02/espanol/america-latina/televisarosa-de-guadalupe-netflix.html

ONU Mujeres. (2020). Hechos y cifras: Poner fin a la violencia contra las mujeres. https://www.unwomen.org/es/what-we-do/endingviolence-against-women/facts-and-figures

Ramírez, J. (2002). La religiosidad latinoamericana y caribeña: un elemento de la identidad cultural. En América Latina y El Caribe. Realidades Sociopoliticas e Identidad Cultural (pp. 215-236). Ediciones Heinrich Böll.

Ramírez, J. (2007). Televisión y violencia. Revista Latinoamericana de Psicología, (39)2, 327-349. https://eprints.ucm.es/id/ eprint/8416/1/311_JMR_Televisio\%CC\%81n_y_violencia.pdf

Roca, L. (2018). La influencia de la creencia guadalupana en la religión, el turismo y la economía. Universidad Santo Tomás. http://hdl. handle.net/11634/10933 
RPP. (6 de agosto de 2014). Estudio sobre identidad: ¿Cómo somos los peruanos? Radio Programas del Perú. https://rpp.pe/lima/ actualidad/estudio-sobre-identidad-como-somos-los-peruanosnoticia-714021?ref=rpp

Soluciones \& Consultoría de marketing (2019). Estudio cuantitativo sobre consumo televisivo y radial en adultos en Lima y provincias. Concortv. http://www.concortv.gob.pe/wp-content/uploads/2019/10/ INFORME-Consumo-TV-y-Radio-2019-ADULTOS.pdf

Trathermberg, L. (10 de enero de 2008). ¿La Idiosincrasia de los Peruanos? León Trathermberg. https://www.trahtemberg.com/articulos/34articulos/238-ila-idiosincrasia-de-los-peruanos.html

Turner, V. (1980). La selva de los símbolos. Siglo XXI Editores.

Vásquez, P. (2011). "La rosa de Guadalupe" como grupo de referencia de las familias mexicanas. Universidad Nacional Autónoma de México. https://www.academia.edu/26526043/_La_Rosa_de_ Guadalupe_como_grupo_de_referencia_de_las_familias_mexicanas 